\title{
Control System Design of CSI Applied in the Battery Pack Testing System
}

\author{
Lixia Zhang', Wei Kang ${ }^{1}$, Rugang Wang ${ }^{2}$
}

${ }^{1}$ College of Information and Control Engineering, China University of Petroleum (UPC), Dongying, China; ${ }^{2}$ Shenzhen Pite Electric Power and Electronics Company, Shenzhen, China.

Email: hdzlx@163.com, zhanglixiaa@hotmail.com

Received April 22 $2^{\text {th }}, 2010$; revised May $9^{\text {th }}, 2010$; accepted May $11^{\text {th }}, 2010$.

\begin{abstract}
This paper designed the loop-locked SVPWM control system of current source inverter (CSI) in the battery pack charging/discharging system. The battery pack is sensitive to the charging/discharging current ripple and orders the current posess fast transform speed. Because the battery pack has tiny inner resistance, back electromotive force and it acted as a comparative load. This made the system hard to design. The control system aimed at the specialty of the battery pack load and put forward a loop-locked control method based on dq coordinate conversion in SVPWM converters. It increases the transform efficiency by SVPWM and gets high power factor and high dynamic response quality by $d q$ coordinate conversion.
\end{abstract}

\section{Keywords: CSI, SVPWM, Dq Coordinate Conversion, Battery Charging, Battery Discharging}

\section{Introduction}

When the battery pack is tested, it needed to be charged and discharged by its testing system converters. There are special requirements to the converter when the battery pack is tested. First, the battery pack is a sensitive load to the converters. When it is charged/discharged, it requires the converter of its testing system to output low-ripple current which has fast response speed. Second, the power grid ordered the converter to be a green grid that validates the properties of high power factor and high conversion efficiency [1,2].

But the inner resistance of the battery pack is very small and it has back electromotive force, when the converter's output voltage is applied on the battery pack, even if the voltage has very little ripples, the current through the battery will be large. Researches showed that both the phased-inverter and the PWM inverter have the problem of outstand current ripple when they are used in battery pack testing [3]. In order to output the regular testing current, traditional way is to use linear regulator converter [4]. But the linear regulator has many disadvantages, such as the low power factor, large power cost $e t$ al. With the development of battery's pack-making technique and its specific energy, the battery testing system is requested to be of high-capacity. Traditional linear regulator mode system can't satisfy the request of the convert-technique.

This paper bring forward a current source PWM con- verter structure which suits for charging/discharging of battery pack, demonstrating the control strategy of current source PWM converter based on dq transformation. It can satisfy the request that the battery pack testing ask for convert technology.

\section{Converter Structure and Work Theory}

For a long time, the study on CSI is much more less than the voltage source inverter (VSI). Most important reasons are that the circuit structure needs big inductance for energy storage and control mode of CSI is more complexity. But when we test the battery pack, converter's output voltage is demanded to accommodate the battery pack in a range of $0-U_{N}$, the voltage source PWM rectifier can offer a fixed DC voltage which is higher than the voltage of power grid. In some conditions that request output DC voltage be lower than power supply, we need a Bucktyped circuit. Or else it's difficult to realize the design of rectifier [5]. CSI offers a steady DC current. Its voltage can be lower than the voltage of power grid. It also has rapid dynamic response when used as DC power, and is convenient for running in four quadrants [6]. It shows that the CSI is more suitable to the design of the rectifier in the battery pack testing system than voltage source PWM rectifier.

According to steady vector connection of AC side of voltage source PWM rectifier, if battery is charged through 
rectifier, the power grid voltage is parallel to the current vector and reverse. At this time, power grid side of rectifier show a negative resistance, power grid absorb positive power, realize the high power factor of battery power to feedback to network [7], (see Figure 1.) The CSI can change the output voltage polarity, but can't change the flow direction of output current. So it can't discharge battery directly through changing the direction of current as voltage source PWM rectifier does. From the above, this paper brings forward a current source PWM converter structure which suits to charge/discharge battery pack, such as Figure 2. $\mathrm{CT}_{1} \sim \mathrm{CT}_{4}$ are thyristors which are used to realize the battery polarity conversion between charging and discharging. In this way, when the battery pack is tested, the double-flow of energy is realized. When dictate current of space current vector and voltage of AC side are in-phase, PWM rectifier is in state of rectification, $\mathrm{CT}_{1}$ and $\mathrm{CT}_{4}$ are cut over and the battery are charged. When dictated current of space current vector and voltage of alternating side are in reverse phase, PWM rectifier is in state of active conversion, $\mathrm{CT}_{1}$ and $\mathrm{CT}_{3}$ conduction are cut over and the battery are discharged. In this time, current and voltage of alternating side of convertor are in reverse phase, network absorb positive power, battery power is feedback to network of high power factor.

Conventional current space vector distribution is showed in Figure 3.

The three phase current space vector can be described as

$$
I_{k}=\left\{\begin{array}{cc}
\frac{2}{\sqrt{3}} i_{d c} e^{j\left(\frac{k \pi}{3}-\frac{\pi}{6}\right)} & (k=1 \sim 6) \\
0 & (k=7,8,9)
\end{array}\right.
$$
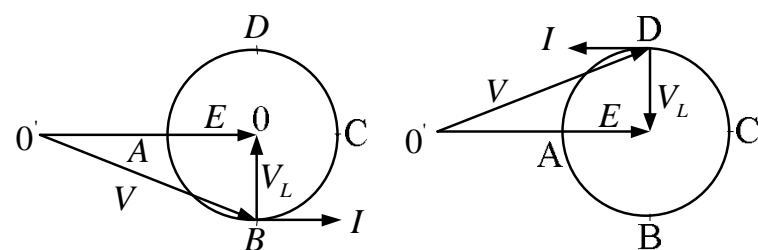

(a) operate as positive impedance; (b) operate as negative impedance

Figure 1. PWM converter stable vector relation of AC side

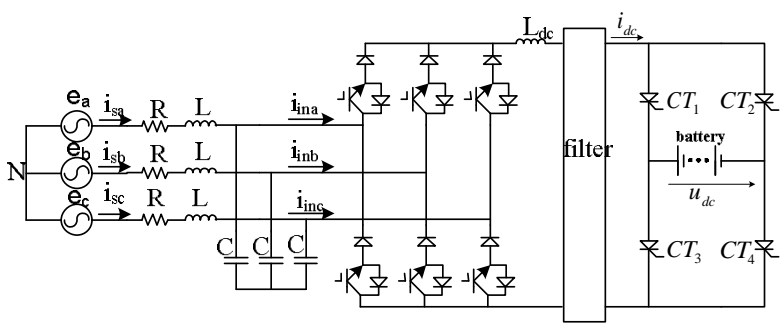

Figure 2. Converter topology of battery pack testing system

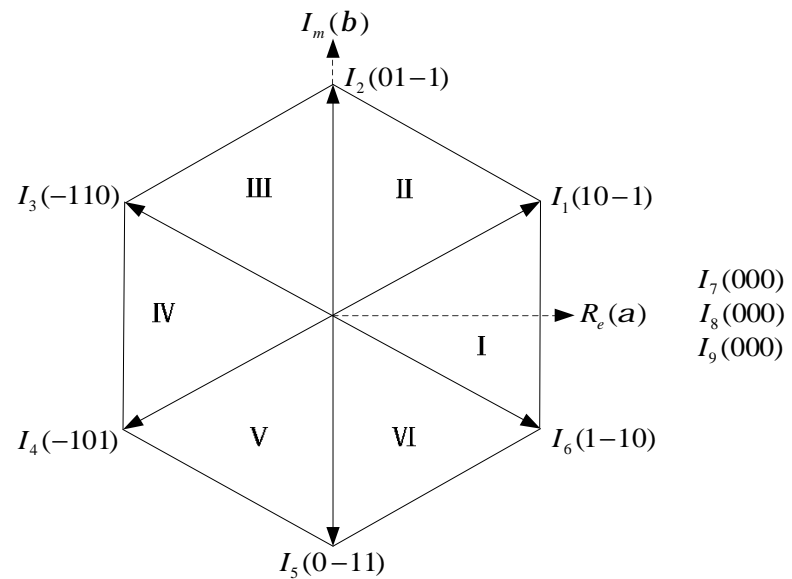

Figure 3. Current space vector distribution

Three phase CSI current space vector modulation equate the composite vector to reference current by appropriate current space vector $I_{k}(k=1 \sim 9)$. All of the reference current $I^{*}$ in arbitrary sector can be composited by current space vector on the side of the sector.

\section{Design of Control System}

The primary control purpose of the battery pack testing system is that: first, regulate current of DC side to fix the tracking parameter; second, gain a demanded power factor and low harmonic content current. Indirect control arithmetic rely on the parameter of CSI main circuit, once the parameter change, the control performance of the current of AC side must be influenced. Direct control of the three-phase CSI current of AC side is through network side current's track trajectory closed loop control. Then operate the alternating current input dictation current number and bring in alternating current feed back to follow dictation current through direct control of alternating current. As the closed loop control also have a suppression to the disturbance in the control loop, to the in DC control, current control of alternating side improved the function of dynamic state and static state by using DC control.

This paper used DC control method which based on the three-phase SCR three-valued logic PWM control. PWM rectifier adopts the SVPWM control mode, because it have a high current efficiency and fast response. Main circle and control structure which based on dq coordinate conversion to SVPWM converters in the battery pack testing system as Figure 4.

The outer loop is DC current control loop. The output $i_{q}^{*}$ of outer control loop is positive current dictate of inner loop. The meaning of $i_{a}^{\prime}, i_{b}^{\prime}, i_{c}^{\prime}$ is the Per Unit System of AC side. Current $i_{a}, i_{b}, i_{c}$ which is in three-phase staticsymmetric coordinate system. If we take abc-dq0 


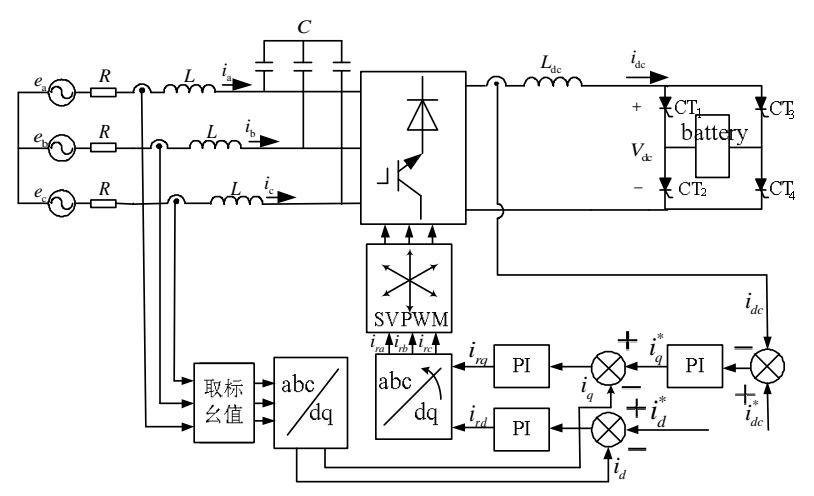

Figure 4. Control structure of current source PWM converter for the battery pack testing system

transform to them, we gain the $i_{d}{ }^{\prime}$ and $i_{a}{ }^{\prime}$ in synchronous revolution coordinate system. Comparing the $i_{d}^{\prime}$ to reactive power component dictate $i_{d}^{*}, i_{q}^{\prime}$ to active power component, we will gain the active power component and reactive power component dictate through regulator.

When rectifier worked in a unit power factor, the reactive power component dictate is zero, active power component output by outer control loop. The order of outer control loop is to fix the DC side current $i_{d c}$. The order of inner control loop is to ask the current $i_{d}$ and $i_{q}$ to keep up with $i_{d}^{*}$ and $i_{q}^{*}$ and to realize the unit power factor and low harmonic current control.

Now we research the structure of three-phase CSI main circuit, for short, we take one phase for example, circuit structure is showed in Figure 4 [8,9].

According the literature [5], we know network side current is formed of two part, one is response to power grid voltage $E_{s}(s)$, the other is response to AC side current. Commonly, PWM equipment can be seen as a self-tuning one-order inertial segment. $W_{P W M}(s) \approx$ $\frac{K_{P W M}}{T_{P W M} S+1}$, when $T_{s}$ is small enough, i.e. $T_{s} \omega<<1$, the PWM equipment can be seen as a proportional component that gain is $K_{P W M}$.

When the switch frequency is outclass the fundamental wave frequency in single-phase CSI network, neglect the harmonic in AC side current $I_{t}(s)$. only take fundamental wave into account. System transfer function

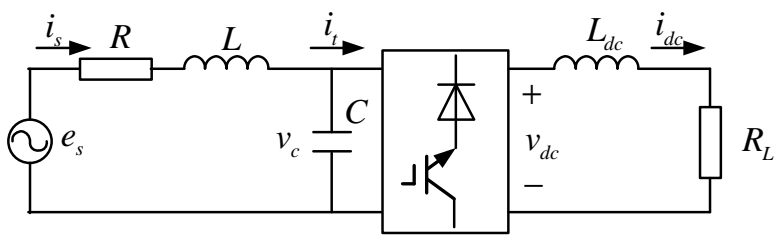

Figure 5. Single-phase CSI circuit transfer structure

is single-variable input and single-variable output. When the power grid voltage fixed, we can neglect the influence that it's ripple produced to the control system. The simplified system two-ring deliver fabric is showed in Figure 6.

\subsection{The Design of Current Inner Control Loop}

For the three-phase CSI control system, consider the relation between the variable of single-phase. From Figure 4, because there are two energy store element $L, C$, the inherent transfer function of the inner loop is $[10,11]$ :

$$
W_{1}(s)=\frac{1}{L C s^{2}+R C s+1}=\frac{1}{\left(\tau_{1} s+1\right)\left(\tau_{2} s+1\right)}
$$

So the inherent transfer function of the inner loop is a 2-order system. The damping ratio $\xi$ and oscillating angular frequency $\omega_{n}$ are,

$$
\begin{gathered}
\xi=\frac{R}{2} \sqrt{\frac{C}{L}} \\
\omega_{n}=\sqrt{\frac{1}{L C}}
\end{gathered}
$$

To design a three-phase CSI control system, first consider one phase. As there are two Energy-Storage component in Figure 4, the AC side current inner loop system's static transfer function is

$$
W_{1}(s)=\frac{1}{L C s^{2}+R C s+1}=\frac{1}{\left(\tau_{1} s+1\right)\left(\tau_{2} s+1\right)}
$$

The inner loop system's inherent transfer function is a second-order system, it's resistance ratio and oscillation angular frequency are:

$$
\begin{gathered}
\xi=\frac{R}{2} \sqrt{\frac{C}{L}} \\
\omega_{n}=\sqrt{\frac{1}{L C}}
\end{gathered}
$$

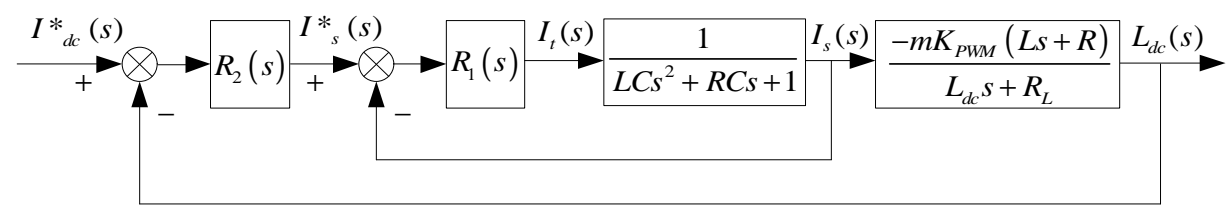

Figure 6. Simplified system two-ring deliver fabric 
Bring the battery's data to Formula (2), then $0<$ $\xi<1$. So this 2 -order system is a periodic damping system. Its two characteristic roots are,

$$
\begin{aligned}
s_{1,2} & =-\xi \omega_{n} \pm j \omega_{n} \sqrt{1-\xi^{2}}=-\xi \omega_{n} \pm j \omega_{d} \\
& =\alpha+j \beta=A e^{-\alpha t} \sin \left(\beta t+\varphi_{0}\right)
\end{aligned}
$$

where $\omega_{d}=\sqrt{1-\xi^{2}} \omega_{n}$ is the damped oscillation frequency.

where $\tau$ is little, $\beta$ is little, so $\sin \beta \tau<<\omega_{n}$, then the imaginary part of the characteristic root can be ignored. Only consider the real par, so

$$
\tau_{1,2} \approx \frac{R C}{2}
$$

Then the inner loop system's inherent transfer function is simplified as

$$
W_{1}(s)=\frac{1}{\left(\tau_{1} s+1\right)^{2}} \quad\left(\tau_{1}=\tau_{2}=R C / 2\right)
$$

In order to attain a good current follow-up control performance for current inner loop, we can set the current inner loop control system with simple model 1. Aimed at simplified inner loop control system transfer function's inherent bi-inertial sector, inner loop control $R_{1}(s)$ can use PI regulator.

$$
R_{1}(s)=W_{\mathrm{pi}}(s)=\frac{K_{\mathrm{pi}}\left(\tau_{\mathrm{pi}} s+1\right)}{\tau_{\mathrm{pi}} s}
$$

Then the open loop transfer function of inner current control loop is

$$
W_{1 o}(s)=W_{\mathrm{pi}}(s) \cdot W_{1}(s)=\frac{K_{\mathrm{pi}}\left(\tau_{\mathrm{pi}} s+1\right)}{\tau_{\mathrm{pi}} s} \cdot \frac{1}{\left(\tau_{1} s+1\right)^{2}}
$$

According to the optimal correction method set it to be a typical I system. The corrected open loop transfer function of inner current control loop is

$$
W_{1 o}(s)=\frac{1}{s\left(\tau_{1} s+1\right)}
$$

The parameter of inner loop PI controller is

$$
\tau_{\mathrm{pi}}=K_{\mathrm{pi}}=\tau_{1}
$$

The transfer function of inner loop is

$$
W_{1 c}(s)=\frac{1}{\tau_{1} s^{2}+s+1}
$$

In the literature [5], the inherent transfer sector of inner loop system can be thought to inertia sector. In order to set inner loop system to 1 system, we regulate the inner loop by integrating device. But if the parameter of integrating device is big, the response will be slow; if use PI of PID rectifier, can reduce the static deviation and have a fast response. So in this paper, we adopt the PI rectifier.

\subsection{Design of Current Outer Loop Rectifier}

According to the transfer function of the inner current loop, because the resistance $\mathrm{R}$ of $\mathrm{AC}$ side is tiny, so $\tau_{1} \omega_{c 2}^{2}<<1$.where $\omega_{c 2}$ is the stop frequency of outer current loop. The transfer function of the inner current loop can be simplified as:

$$
W_{1 c}(s)=\frac{1}{s+1}
$$

when the power grid voltage is steady, the disturbance of power grid voltage Es(s) and DC current EL(s) can be neglected. The transfer function from $i_{s}$ to $i_{d c}$ is $\frac{-m K_{P W M}(L s+R)}{L_{d c} s+R_{d c}}$, The transfer function of the inner current loop is,

$$
W_{2 o}(s)=R_{2}(s) \cdot \frac{1}{s+1} \cdot \frac{-m K_{P W M}(L s+R)}{L_{d c} s+R_{d c}}
$$

where $R_{2}(s)$ outer current PI transfer function, $\mathrm{m}$ is the modulation ratio.

The outer current control system is set as a typical II system. $R_{2}(s)$ is designed by PI controller, its transfer function is,

$$
R_{2}(s)=W_{p i}(s)=\frac{K_{p i}^{\prime}\left(\tau_{p i}^{\prime} s+1\right)}{\tau_{p i}^{\prime} s}
$$

where $K_{p i}^{\prime}$ is the proportional gain $\tau_{p i}^{\prime}$ is the leading time consrant of PI regulator

The adjusted transfer function of outer current loop is,

$$
W_{2 o}(s)=\frac{K_{p i}^{\prime}\left(\tau_{p i}^{\prime} s+1\right)}{\tau_{p i}^{\prime} s} \frac{1}{s+1} \frac{-m K_{P W M} R\left(\frac{L}{R} s+1\right)}{R_{d c}\left(\frac{L_{d c}}{R_{d c}} s+1\right)}
$$

when $\left(L_{d c} / R_{d c}\right) \omega<<1$,

$$
W_{2 o}(s)=\frac{K_{p i}^{\prime}\left(\tau_{p i}^{\prime} s+1\right)}{\tau_{p i}^{\prime} s} \frac{1}{s+1} \frac{-m K_{P W M} R\left(\frac{L}{R} s+1\right)}{R_{d c}\left(\frac{L_{d c}}{R_{d c}} s+1\right)}
$$

when $\frac{L}{R}$ is little, simplify the system by merging little time constant. The transfer function of outer current loop is,

$$
W_{2 o}(s) \approx \frac{-m K_{P W M} R K_{p i}^{\prime}}{\tau_{p i}^{\prime} L_{d c}} \frac{\left(\tau_{p i}^{\prime}+\frac{L}{R}\right) s+1}{s^{2}(s+1)}
$$


Design the outer current loop by typical II system. The frequency factor $h=5$, then $h=5$, the transfer function of outer current loop is,

$$
\left\{\begin{array}{l}
\tau_{p i}^{\prime}=5-\frac{L}{R} \\
K_{p i}^{\prime}=-\frac{L_{d c}}{m K_{P W M} R}\left(5-\frac{L}{R}\right)
\end{array}\right.
$$

\section{Research of Emulation}

The testing system charges/discharges the battery pack by control of double closed loop emulation designed from Figure 4. Parameter of emulation as follows. The phase force is $70.7 \mathrm{~V}$. The terminal voltage of the battery is $32 \mathrm{~V}$. The energy storage inductance is $3 \mathrm{mh}$. The filter parameter is designed by $\omega=150 \pi, A_{p}=0.05$. the inner resistance of the battery is $R=0.3 \mathrm{ohm}$. the designed filter parameter is $L_{1}=1.2 \mathrm{mH}, C=8800 \mu \mathrm{F}, L_{2}=$ $0.9 \mathrm{mH}$, the AC side filter parameter $L=0.3 \mathrm{mH}$, $C=880 \mu \mathrm{F}$, the step length is $1 / 51200 / 20$. The PI parameter of inner current loop is $\tau_{p i}=0.11, K_{p i}=30$. The PI parameter of outer current loop is $\tau_{p i}^{\prime}=0.1$, $K_{p i}^{\prime}=0.1$. When the instruct current inversed, the polarity of battery inverse, and the current source PWM converter worked at $\mathrm{AC}$ inversion state. The battery is discharged and its energy feed back to the power grid. The PI parameter of outer current loop is $\tau_{p i}=0.1, K_{p i}=0.08$, The PI parameter of inner current loop is $\tau_{p i 1}^{\prime}=0.4$, $K_{p i 1}^{\prime}=65, \tau_{p i 2}^{\prime}=0.4, K_{p i 2}^{\prime}=65$. The terminal voltage of the battery is $80 \mathrm{~V}$, and the other parameter is the same with when the battery is charged.

From the emulation, we can see that whether DC side is charging or discharging, there is a low ripple and fast response. Through spectrum analysis of testing current, we know that the harmonic percent of charging current is $0.1 \%$, discharging current is $0.05 \%$ and this fulfill the request of testing current ripple. If network side voltage and current are in-phase when charging, network side of rectifier show a negative resistance, network absorb positive power, realize the high power factor of battery power to feedback to network.

\section{Experimental Procedure and Discution}

\subsection{Experimental Procedure}

In order to validate the correctness of structure and control method, this paper have done a sample of current source SVPWM convertor based on dq transformation and experienced with VRLA piles. Main circuit and structure is showed in Figure 3. This system used the TMS320F2812 of TI company as main control CMOS chip and switch frequency is $1.6 \mathrm{kHz}$. The parameter of DC side filter

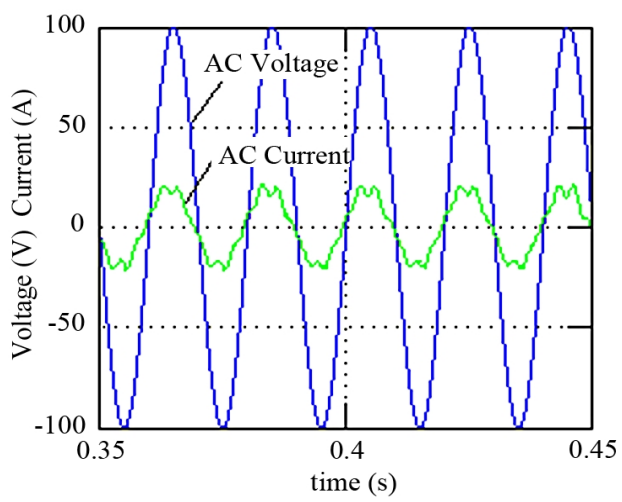

(a)

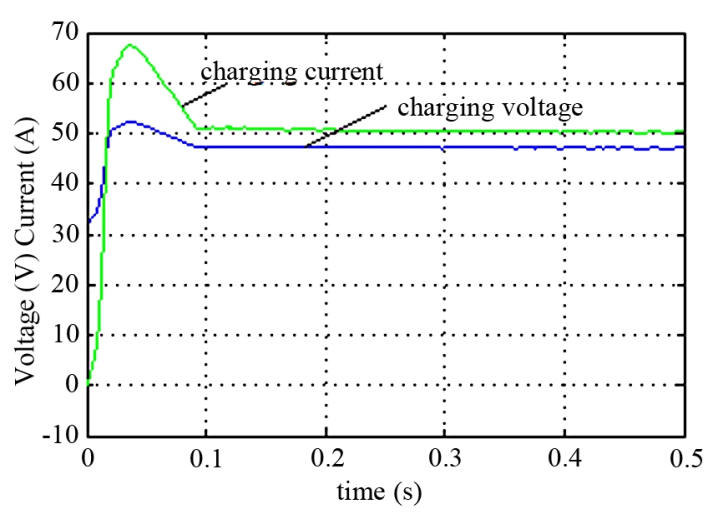

(b)

(a) the current and the voltage of the AC side; (b) the current and the voltage of the DC side

Figure 7. Simulation result when the charging current $I_{\mathrm{dc}}^{*}$ $=\mathbf{5 0 A}$

is same to the emulation parameter. The sample uses a $9 \mathrm{~kW}$ booster to supply voltage. The voltage of piles is $12.8 \mathrm{~V}$ and output voltage of transformer $23.8 \mathrm{~V}$ when experiencing. It takes use of DL1600 digital oscilloscope to observation the result of the experience and copy waveform, which was produced by Japanese YOKOGAWA Company. The waveform is saved as a *.csv file and disposed in MATLAB. The data is analyzed by FFT to certify the output performance of the filtering result.

After filtering, the current harmonic of power gride side and DC side are all low, for example, if DC side's current harmonic is beyond $0.5 \%$, corresponding, DC near to $100 \%$. If we put DC and other harmonic current in the same histogram, those whose content is lower than $1 \%$ will be dimness and difficult to see. So DC's spectrum analysis output neglect the DC $I_{0}$ which as a consult as to observe the other harmonic's spectrum distribution.

From the double closed loop charging test, we can see that AC side voltage and current are in-phase when charging; DC side output a current who has low ripple and fast response. When discharging the voltage and the cur- 


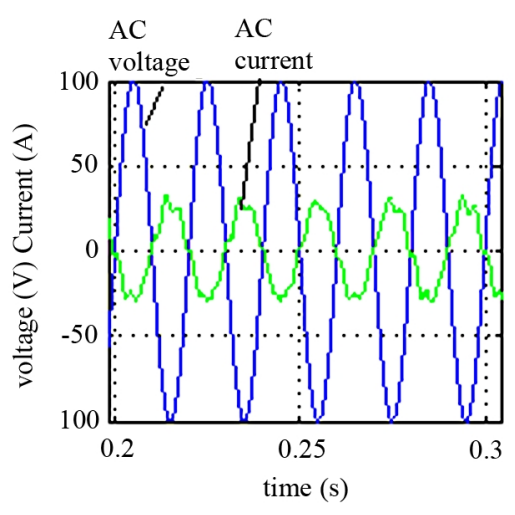

(a)

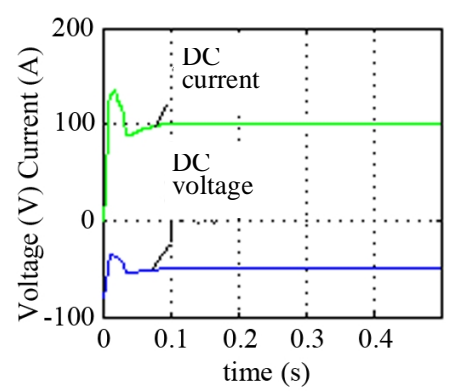

(b)

(a) the current and the voltage of the $\mathrm{AC}$ side; (b) the current and the voltage of the DC side

Figure 8. Simulation result when the discharging current $I_{\mathrm{dc}}^{*}=100 \mathrm{~A}$

rent out phase, the battery's energy feed back to the power grid with a high power factor.

\subsection{Discussion: Analyze of Error}

Analyzing the experiment, there are two main influence, inner resistance of filtering inductance and three-phase voltage unbalance.

1) To measure the inductance in this experiment by two-bridge method, it's resistance is $0.1 \mathrm{ohm}$. Those elements who have wastage will make the transmitted function pole of filter move left, so influence the propagation properties. As the literature [6] validate, the wastage of inductance will influence the filtering performance of filter. This is one of the important reason that make deviation between the experiment result and emulation.

But battery pack testing system need a 500A output current of rectiformer. We need an inductance with thick diameter, a DC with small resistance and the influence of transmitted performance to transformer can be neglected. So the filter designed in this paper which has small wastage, fast response can satisfy the request of battery pack testing system.

2) There are a lot of 2-order harmonics in the spectrumof steady State current. Though the experiment realized

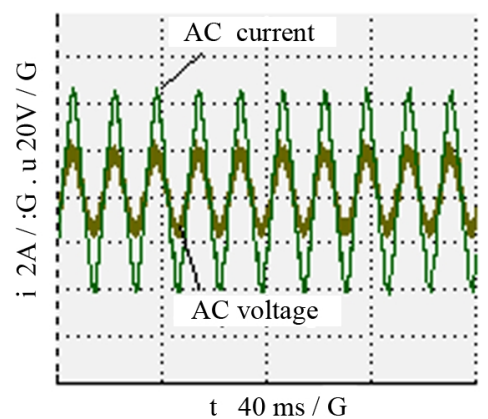

(a)

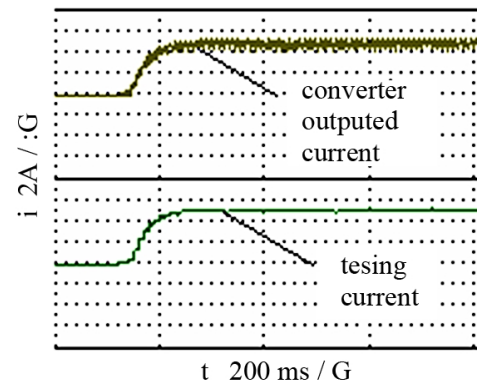

(b)

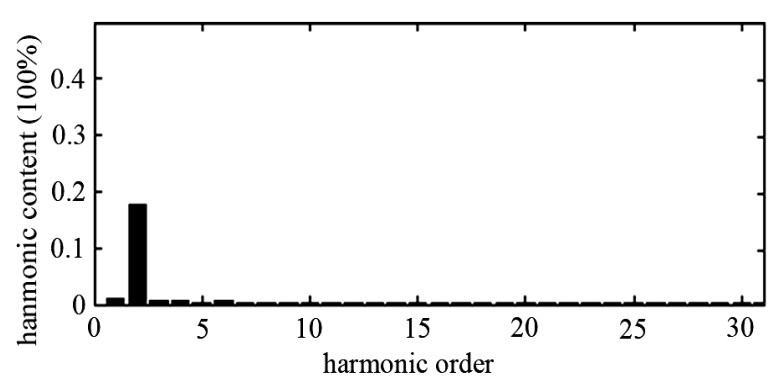

(c)

(a)voltage and current of the power grid side; (b)the test current and the converter outputted current; (c)spectrum analysis for the charging current

Figure 9. 5A battery charging test by current source SVPWM converter controlled by 2-closed loop

to make voltage and current in same phase, the current waveform of AC side is not perfect sine wave. Through measure the three-phase voltage of power, we find a phenomenon that the power in experiment is Three-Phase Unbalance and the three-phase voltage have thrice harmonic. All this will influence the result of the experiment result.

Some research $[7,8]$ show that three-phase CSI direct voltage will produce $6,12,18$ characteristic harmonic and 2,4,8,10 Non-characteristic Harmonic when three-phase unbalance. Direct voltage harmonic lead rectifier to produce DC current harmonic, in reverse, the DC current harmonic influence the waveform of alternating current current. That's to say, after PWM control, three-phaseCSI DC side's harmonic current will produce $n+1$ harmonic current in $\mathrm{AC}$ side of rectifier. 


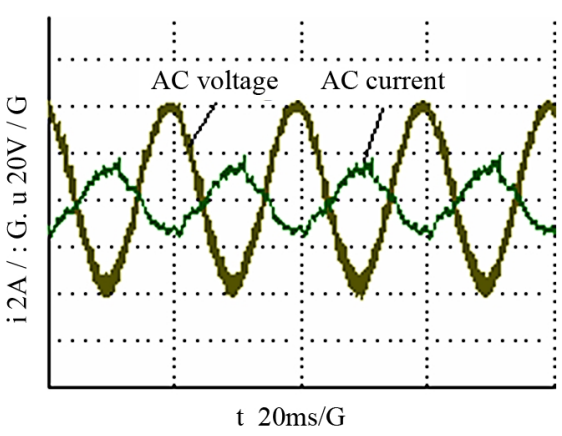

(a)

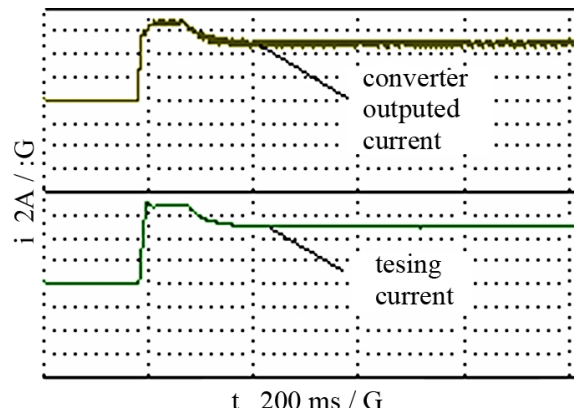

(b)

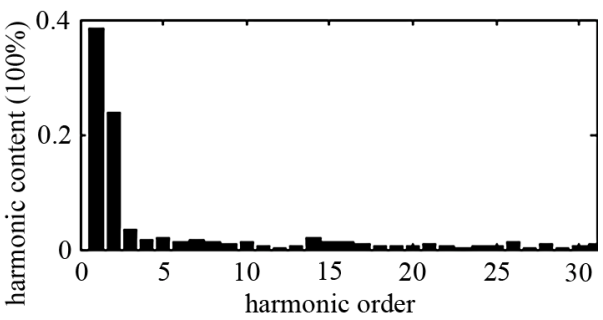

(c)

Figure 10. 5A battery discharging test by current source SVPWM converter controlled by 2-closed loop: (a) voltage and current of the power grid side; (b) the test current and the converter outputted current; (c) spectrum analysis for the charging current

From the result of experiment, after filtering, there are very little harmonic after 5 in current spectruma analyze. This is because that the design of filter's stop band frequency is 6 order harmonic. The decay to the harmonics that the order is bigger than 6 is $6 n \mathrm{~dB}$ larger per sound interval than the 6-order harmonics. So the harmonic after 5 will be suppressed, also, harmonic in pass band will be suppressed too such as 2 harmonic just because of the DC filter we designed have enactment to the minimum attenuation.

When network's voltage is unbalanced, we can suppress the 2-order harmonic through proper control of three-phase CSI. Now there already have some research about the suppression of 2 harmonic in voltage source PWM DC side $[9,10]$. This method should be brought
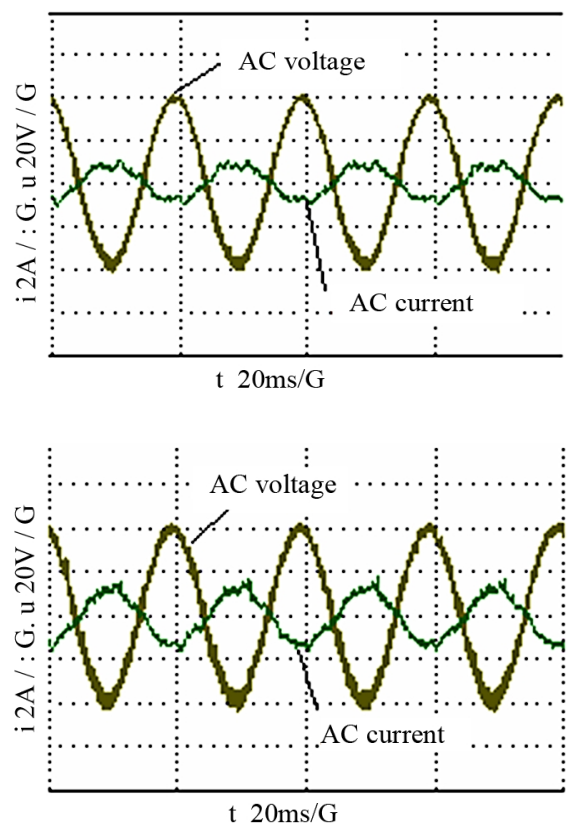

Figure 11. The voltage and current of power grid in $2 \mathrm{~A}, 4 \mathrm{~A}$ SVPWM discharging test

into the CSI. This paper will make this problem as the latter research and discuss deeply.

3) When discharging, the resistance changed and the equivalent resistance of charging/discharging is not the same [12]. Though this paper realize the double closed control in battery pack, there are some different between experiment result and emulation result when discharging, for example, a long time for system to Response, response speed slower than charging experiment. This is because the program is not perfect. So, the parameter of double closed loop control should be regulated according to resistance when charging.

\section{Conclusions}

CSI assisted with polar switch circuit can realize regulation of output voltage and current, attain the double-flow of energy; Double closed loop control system based on dq coordinate conversion to SVPWM converters used in the battery pack testing system. It's advantage of "fast response, high efficiency of energy conversion, bidirectional converting, high power factor of power grid side.

\section{Acknowledgements}

This research is supported by doctorate found of China University of Petroleum.

\section{REFERENCES}

[1] J. Bauman and M. A. Kazerani, "Comparative Study of Fuel Cell-Battery, Fuel Cell-Ultracapacitor, and Fuel Cell-Battery-Ultracapacitor Vehicles," Vehicular Technology, IEEE Transactions on, Vol. 57, No. 2, 2008, pp. 760-769. 
[2] L. X. Zhang, X. W. Yan, H. Li, et al., "Design and Simulation of Fast-Response Filter Based on Locomotive Battery Testing System," Proceedings of 12th International Power Electronics and Motion Control Conference EPE-PEMC'06, Portoroz, 30 August-1 September, 2006.

[3] L. X. Zhang, X. W. Yan, H. Li, et al., "Design Method of Low Loss and Fast Response LC Filters Based on Locomotive Battery Testing System," EPE Journal, Vol. 18, No. 1, 2008.

[4] L. X. Zhang, K. Wei and J. Li, "Control of Bidirectional Current Source SVPWM Converter in the Power Accumulator Battery Testing System," Proceedings of AsiaPacific Power and Energy Engineering Conference, Chengdu, 2010.

[5] B. Bhargava and G. Dishaw, "Application of an Energy Source Power System Stabilizer on the 10 MW Battery Energy Storage System at Chino Substation," Power Systems, Vol. 13, No. 1, 1998, pp. 145-151.

[6] A. Davis, Z. M. Salameh and S. S. Eaves, "Comparison of a Synergetic Battery Pack Drive System to a Pulse Width Modulated AC Induction Motor Drive for an Electric Vehicle," Energy Conversion, Vol. 14, No. 2, 1999, pp. 245-250.

[7] S.-H. Lee, S.-G. Song, S.-J. Park, et al., "Grid-Connected
Photovoltaic System Using Current-Source Inverter," Solar Energy, Vol. 82, No. 5, May 2008, pp. 411-419.

[8] H. F. Ding, S. Y. Shu, X. Z. Duan, et al., "A Novel Dynamic Voltage Restorer and its Unbalanced Control Strategy Based on Space Vector PWM," International Journal of Electrical Power \& Energy Systems, Vol. 24, No. 9, November 2002, pp. 693-699.

[9] X. Zhang, J.-Q Ji, C.-W. Zhang, et al., "Study of Internal Model Control Based Three-Phase PWM Rectifier under Unbalanced Input Voltage Condition," Proceedings of the CSEE, Vol. 25, No. 13, 2005, pp. 51-56.

[10] J.-B. Xu, D.-X. He, J. Zhao, et al., "A New Power Analysis Method of PWM Rectifier with Unbalanced Voltage Condition," Proceedings of the CSEE, Vol. 26 No. 16, 2006, pp. 80-85.

[11] K.-G. Zhao, F. Pei, X.-D. Huang, Y.-T. Luo, et al., "Variable Current dischargeable Characteristics and SOC Estimation of EV/HEV Battery[J]," Proceedings of the CSEE, Vol. 25, No. 9, 2005, pp. 164-168.

[12] J.-P. Randin, "Reliability of Commercial Lithium Button Cells II. Effect of The State-of-Discharge and Environment on the Passivation Resistance," Journal of Power Sources, Vol. 25, No. 1, January 1989, pp. 61-74. 